\title{
Characterization of wastewater from landfills - amount and type of humic substances extracted from leachate
}

\author{
Maria Elisabete Silva ${ }^{1,2}$, Marlene Santos ${ }^{3}$, and Isabel Brás ${ }^{1}$ \\ ${ }^{1}$ Departamento de Ambiente, Escola Superior de Tecnologia e Gestão de Viseu, Campus Politécnico, CI\&DETS, Instituto Politécnico de \\ Viseu, 3504-510 Viseu, Portugal \\ ${ }^{2}$ LEPABE, Laboratório de Engenharia de Processos, Ambiente, Biotecnologia e Energia, Faculdade de Engenharia, \\ Universidade do Porto, Portugal \\ ${ }^{3}$ Departamento de Ambiente, Escola Superior de Tecnologia e Gestão de Viseu, Campus Politécnico, 3504-510 Viseu, Portugal
}

\begin{abstract}
This study aimed to characterize the humic substances (HS) extracted from landfills wastewater - leachates, with different ages of exploration. To reach the objective it was applied spectroscopy techniques, UV-Vis and FTIR spectra, as well as the ratio between the absorbance analysed. First, the HS were extracted, then fractionated in fulvic acids (FA) and humic acids (HA) and it was evaluated the phytotoxicity. HS content in the leachates were higher than the typical values found in the natural aquatic humic sources. It has been identified that the leachate HS, HA and FA aromatic fractions increased with the increase of the landfilling age, suggesting that the degree of humification increased with the landfilling age. All the HS showed a high aromaticity and humification degree. The HS extracts irrespective of their source presents similar structural composition. The functional groups found are in agreement with the literature: phenols, alcohols, carboxylic groups, aliphatic structures, among others. It was found that HA are mainly organic matter with a higher aromatic degree than FA. The HS and HA showed absence of phytotoxicity, testing by germination index, suggesting that may be used to produce liquid organic fertilizers.
\end{abstract}

\section{Introduction}

The disposal of solid wastes in sanitary landfills represents nowadays the most common method of waste management. Leachates or wastewater produced in landfills are generated mainly due to rainwater percolation through wastes and their decomposition products [1], leading to a complex mixture of high strength organic and inorganic contaminants [2]. Moreover, the recalcitrant organic contaminants may include humic substances (HS), phthalic esters, pesticides, and many other emerging organic pollutants [3]. The refractory HS include humic acids (HA), fulvic acids (FA) and humin that are produced during the decomposition of the biodegradable fraction of organic compounds in leachates. These compounds have a major role as fertilizers and land correctives, which may contribute to the essential functions of global soil fertility. In particular, the role of humic acids should be emphasized. For example, it addition to soil has a positive effect on the assimilation of nutrients by plants and microorganisms. Indeed, nowadays there is a growing tendency to use humic substances as liquid organic amendment, produced from natural resources such as leonardite, peat, and lignite $[4,5]$, but their use could be a contribute to the extinction of these natural resources. Thus, it is important to find other sources of these substances, such as the leachate. In general, HS are composed of chemically complex organic compounds, which are largely hydrophilic, acidic and polydisperse [6]. In nature, HS, mainly HA and humin, are extremely resistant to biodegradation. Indeed, given their low decomposition, HS belong to the group of stable natural organic compounds [7]. Despite great efforts to elucidate the still unknown HS structure, it is known that their major functional groups include carboxylic, phenolic, carbonyl, hydroxyl, amine, amide and aliphatic moieties, among others [8]. Briefly, HS are composed of a very large variety of aromatic rings (phenolic and quinonic) bound by acid functional groups or by peripheral aliphatic chains (polysaccharides, peptides, etc) and grouped into the different molecular arrangements that make up the HS structure [9].

In this study, an array of analyses was performed to characterize HS extracted from two landfills with different landfilling ages in order to chemically stablish their structural composition and related them with the landfill exploration period. Additionally it was evaluated their phytotoxicity

\section{Materials and Methods}

Three leachates samples from two Municipal Solid Waste (MSW) landfills - Bg and Pl - with different landfilling ages were used to carry out this study. They are located in the north of Portugal. Samples were 
collected at different operating stages corresponding to 12 years for landfill $\mathrm{Bg}$ and 16 and 17 years for Pl (samples code P1_1 and P1_2, respectively).

\subsection{Humic Substances Extraction}

Leachate extraction for humic substances (HS) was performed by the acid-base treatment method [10]. Briefly, leachate samples were filtered through $0.45 \mu \mathrm{m}$ cellulose membrane filters and acidified to $\mathrm{pH} 2.0$. Acidified leachate samples were percolated through a XAD-8 (Supelite DAX-8, Supelco) resin column. The preparative cleaning of the resin is described by Thurman and Malcom [11]. After percolating the whole sample through the adsorption column, HS were eluted from the XAD-8 resin using $0.1 \mathrm{M} \mathrm{NaOH}$, in reverse flow. The HS fractionation in FA and HA was achieved by a selective precipitation process with $\mathrm{pH}$ control, using concentrate sulphuric acid. The resultant HS was fractionated by $1.5 \mathrm{~mL} 96 \% \mathrm{H}_{2} \mathrm{SO}_{4}$ addition ( $\left.\mathrm{pH} 2\right)$. After $24 \mathrm{~h}$ at room temperature and centrifugation for $20 \mathrm{~min}$ at $4000 \mathrm{rpm}$, the insoluble fraction, which contained humic acid substances (HA fraction), was separated from the soluble fulvic acid substances (FA fraction). HA was dissolved in distilled water [12]. The total organic carbon (TOC) content of HS, HA and FA was measured in terms of $\mathrm{mg}$ TOC/L using a TOC-L CSN analyzer (Shimadzu).

\subsection{Humic Substances Chemical Characterization}

The absorbance of the HS, HA and FA fractions were measured at $254 \mathrm{~nm}, 280 \mathrm{~nm}, 465 \mathrm{~nm}$ and $665 \mathrm{~nm}$ in a UV-VIS spectrometer (Jenway 6300 Spectrophotometer). The ratio of quantified absorbance E254/E465, E280/E465, E280/E665, E465/E665 were evaluated and interpreted.

The functional groups of samples were identified by Fourier transform infrared (FTIR) covering a wavenumber range of $400-4000 \mathrm{~cm}^{-1}$. FTIR spectra were recorded on a Bruker Tensor 27 spectrophotometer using $\mathrm{KBr}$ pellets. The FTIR evolution was followed by establishing ratios between absorbance at: $1034 \mathrm{~cm}^{-1}$, $1235 \mathrm{~cm}^{-1}, 1384 \mathrm{~cm}^{-1}, 1544 \mathrm{~cm}^{-1}, 1652 \mathrm{~cm}^{-1}, 2925 \mathrm{~cm}^{-1}$.

\subsection{Phytotoxicity Tests}

The phytotoxicity evaluation was conducted performing germination tests, using Lepidium sativum (water cress) as tested seed. This bioindicator was chosen due to its rapid growth and high sensibility to pollutants. All the tests were done using seven replicates with fifteen seeds, in Petri dishes with sterile filter paper humidified with 4 $\mathrm{mL}$ of the testing solution. Blank tests were also done. A leonardite based commercial liquid fertiliser (Humistar ${ }^{\circledR}$ ) was included as control. The germination index (GI, \%) was evaluated by equation 1 .

$$
\mathrm{GI}=\frac{\mathrm{GS}_{\mathrm{s}} \cdot \mathrm{RL}_{\mathrm{s}}}{\mathrm{GS}_{\mathrm{c}} \cdot \mathrm{RL}_{\mathrm{c}}} * 100
$$

Where $\overline{\text { GS }}$ represents de average number of germinated seeds and $\overline{\mathrm{RL}}$ the average root length $(\mathrm{mm})$ of seeds in samples $-\mathrm{s}$, and the blank $-\mathrm{c}$ tests.

\section{Results and Discussion}

\subsection{Humic Substances Quantification}

After extraction of HS from the landfills leachates and their fractionation it was possible to quantify the HS, HA and FA (Table 1). The HS amount was similar for all the leachates evaluated and was higher than $780 \mathrm{mg} / \mathrm{L}$ of total organic carbon. All the leachates analysed registered higher FA concentration than HA. These results were higher than the reported by Fan et al that ranged between 100 and $202 \mathrm{mg} / \mathrm{L}$ for FA and 72 and $101 \mathrm{mg} / \mathrm{L}$ for HA [13]. Moreover, the amount found of HS was greater than the reported for the natural aquatic resource of HS [4]. Overall, the data indicate that the leachate may be a source of HS, because the high carbon content of the samples.

Table 1. Quantification of HS, FA and HA obtained from the landfill leachates

\begin{tabular}{|c|c|c|c|}
\hline $\begin{array}{c}\text { Landfill } \\
\text { Leachate }\end{array}$ & $\begin{array}{c}\text { HS [mg } \\
\text { TOC/L] }\end{array}$ & $\begin{array}{c}\text { FA [mg } \\
\text { TOC/L] }\end{array}$ & $\begin{array}{c}\text { HA [mg } \\
\text { TOC/L] }\end{array}$ \\
\hline Bg & 839 & 677 & 28 \\
\hline PI_1 & 780 & 288 & 30 \\
\hline PI_2 & 1311 & 966 & 131 \\
\hline
\end{tabular}

Once, the FA concentrations values are higher than the HA, is possible to state that the landfills are not in the maturation phase [14]. These results suggest that the HS from landfill leachates were in an early stage of humification, once the degree of humification increase as the landfilling age increase.

\subsection{UV-Vis Spectrum Analysis}

UV absorption of HS, HA and FA is used to evaluate the condensation level of humic aromatic core indicating the maturation degree [15], and to analyse their molecular properties [16-18]. There are three important regions in the spectrum where exact absorbance is measured. Zbytniewski and Buszewski [14] enlightened that UVVis analysis of alkali extracts is generally based on the assumption that the absorbance at $260-280 \mathrm{~nm}$ is due to lignin and quinone moieties. The absorbance at $254 \mathrm{~nm}$ gives the total dissolved organic matter in the solution and the values at $280 \mathrm{~nm}$ show the organic matter aromaticity degree [19]. The absorbance at $465 \mathrm{~nm}$ reflects the organic material at the beginning of humification and the absorbance at $665 \mathrm{~nm}$ is referred to be indicative of strongly humified material with a high degree of aromatic and condensed groups [16]. Therefore, the absorbance ratios have been calculated 
E254/E465, E280/E465, E280/E665, E465/E665, and may be used to determine the degree of maturation (humification) of organic matter [20]. The E254/E465 ratio point to the proportion of the dissolved total organic matter and the organic matter at the humification beginning, indicating the biodegradable organic matter at this point. The E280/E465 reflects the proportion between the lignin and quinone and the content of organic matter at beginning of humification. E280/E665 ratio denotes the relation between aromatic organic material and strongly humified material [14]. The $\mathrm{E} 465 / \mathrm{E} 665$ ratio is used to indicate the degree of condensation and polymerization of the aromatic constituents, and can fulfill the function of humification index [21]. It can also be used as an indicator of molecular weight [22]. In Figure 1, these ratios are represented. From these data is possible to record that the ratio for HS, HA and FA have a similar trend for the three samples. The values obtained in increasing order were the following: E465/E665, E280/E465, E254/E465 and E280/E665 ratio. Indicating that the 3 fractions present a high degree of humification (E465/E665 low) and additionally a high degree of aromaticity, namely the possible presence of phenolic and carboxylic groups (high E280/E665). For all cases, HA have a lower ratio than the other humic structures (HS and FA).

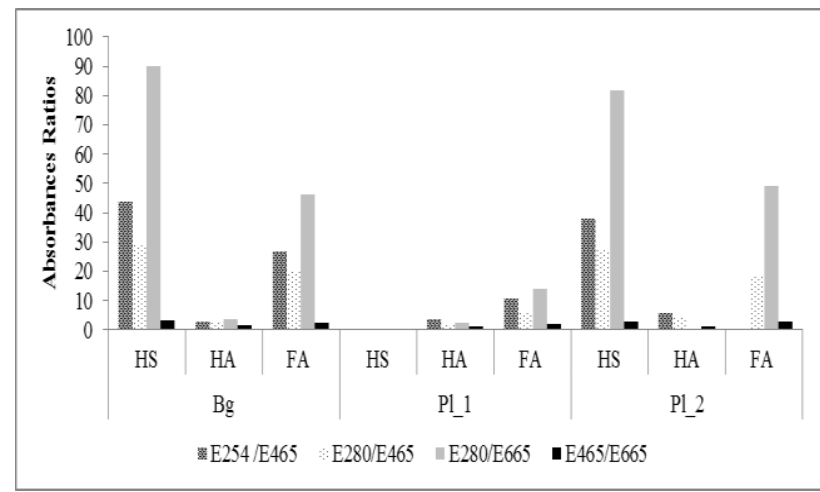

Fig. 1. Absorbance ratios of the humic substances extracted from the landfill leachates.

\subsection{FTIR Spectrum Analysis}

The changes in FTIR spectrum have been reported in the literature by calculating the ratio between the intensities of the major peaks absorption, this may be used as a tool for the study of humic structures evolution [25-26] and thereby the humification process. The FTIR absorbance evolution of humic structures was followed by establishing the ratios [17, 25-28]: 1652/2925 (aromatic $\mathrm{C}=\mathrm{C}, \mathrm{COO}^{-} /$aliphatic $\left.\mathrm{C}-\mathrm{H}\right) ; 1652 / 1544$ (aromatic $\mathrm{C}=\mathrm{C}$, $\mathrm{COO}^{-} /$amide II N-H); 1652/1384 (aromatic $\mathrm{C}=\mathrm{C}, \mathrm{COO}^{-}$ /stretching $\mathrm{N}-\mathrm{O}$ ); 1652/1235 (aromatic $\mathrm{C}=\mathrm{C}, \mathrm{COO}^{-} /$ aromatic ethers C-O-C, amide III); 1544/2925 (amide II $\mathrm{N}-\mathrm{H}$ / aliphatic C-H); 1544/1384 (amide II N-H / stretching N-O); 1384/2925 (stretching N-O / aliphatic $\mathrm{C}-\mathrm{H}$ ); 1034/2925 (polysaccharides C-O/aliphatic C-H); 1034/1235 (C-O polysaccharide/ ethers aromatic, amide
III C-O-C). These results are described in Table 2. The ratios changed between 0.96 and 1.50 , values that were in accordance with those found by other authors that reported ratio values between 0.53 and 1.53 [25-26, 28]. The ratio data followed the increasing order: $1034 / 1235<1034 / 2925<1384 / 2925<1544 / 1384<1544 / 29$ $25<1652 / 1384<1652 / 1543<1652 / 1235<1652 / 2925$. This suggests that the 3 fractions are mainly constituted by aromatic $\mathrm{C}=\mathrm{C}$ and $\mathrm{COO}^{-}$than aliphatic $\mathrm{C}-\mathrm{H}$, because the high 1652/2925 (aromatic C/aliphatic C) ratio. Overall, similar values were found for the 3 fractions analysed (HS, HA and FA), however the HA fractions registered a slightly high value for this ratio, followed by HS and then by FA. These results are in accordance with the higher aromatic character of the HA than the other humic structures. The data from the ratios showed an increase mainly by the intensity of structures absorbing at 1652,1544 and $1235 \mathrm{~cm}^{-1}$ with a relative decrease of absorbance at $2925 \mathrm{~cm}^{-1}$. This suggests a richness of humic structures in aromatic compounds and a loss of readily available aliphatic compounds from these macromolecules, mainly polysaccharides, as result of their oxidation.

FTIR spectra of $\mathrm{HA}$ for leachate $\mathrm{Pl} 1$ and $\mathrm{Pl} 2$ samples are represented in Figure 2. According with the information reported by other authors [2, 18, 27] is possible to state that the HA extracted from these samples have in their constitution the following functional groups: $\mathrm{O}-\mathrm{H}$ bonds, evidencing the presence of phenols, alcohols and carboxylic groups as can be seen by the absorption band at $3400-3200 \mathrm{~cm}^{-1}$ (stretching). The absorption spectrum for P1 2 sample, from the older landfill has a stronger evidence of the carboxylic acids once the absorption band is shifted to lower values of wave numbers. The band at 3180-3090 $\mathrm{cm}^{-1}$ evidence the stretching of $\mathrm{NH}_{2}$ bonds indicating the presence of primary amides. The band at $1640-1600 \mathrm{~cm}^{-1}$ represent $\mathrm{C}=\mathrm{O}$ stretching bonds indicative of amides, carboxylates and aromatic rings; the band at 1140-1080 $\mathrm{cm}^{-1}$ represent the stretching vibrations from links of S-O relative to inorganic sulfates and the band at 750-700 $\mathrm{cm}^{-1}$ suggest $\mathrm{N}-\mathrm{H}$ bonds indicative of secondary amine groups. It is also interesting to notice the band comprised between $2100-2000 \mathrm{~cm}^{-1}$, which indicates the presence of cyanide ions, that it is also not common in this kind of substances [29].

In general, it is possible to conclude that the functional groups observed are in agreement with those registered in the literature $[2,27]$, therefore with the molecular characterization of substances. 
Table 2. Absorbance ratio in mid-infrared measured by FTIR.

\begin{tabular}{|c|c|c|c|c|c|c|c|c|c|c|}
\hline & & $1652 / 2925$ & $1652 / 1544$ & $1652 / 1384$ & $1652 / 1235$ & $1544 / 2925$ & $1544 / 1384$ & $1384 / 2925$ & $1034 / 2925$ & $1034 / 1235$ \\
\hline \multirow[t]{3}{*}{ Bg } & HS & 1.14 & 1.02 & 1.08 & 1.04 & 1.13 & 1.06 & 1.06 & 1.07 & 0.98 \\
\hline & HA & 1.43 & 1.27 & 1.31 & 1.31 & 1.13 & 1.03 & 1.09 & 1.11 & 1.01 \\
\hline & FA & 1.32 & 1.15 & 1.20 & 1.19 & 1.15 & 1.04 & 1.10 & 1.15 & 1.03 \\
\hline \multirow[t]{3}{*}{ PI_1 } & HS & 1.33 & 1.17 & 1.20 & 1.23 & 1.14 & 1.03 & 1.11 & 1.09 & 1.00 \\
\hline & HA & 1.50 & 1.41 & 1.45 & 1.47 & 1.06 & 1.03 & 1.03 & 1.02 & 0.99 \\
\hline & FA & 1.28 & 1.14 & 1.19 & 1.19 & 1.12 & 1.04 & 1.08 & 1.09 & 1.01 \\
\hline \multirow[t]{3}{*}{ PI_2 } & HS & 1.12 & 1.00 & 1.01 & 1.07 & 1.12 & 1.02 & 1.10 & 1.02 & 0.97 \\
\hline & HA & 1.06 & 1.03 & 1.01 & 1.02 & 1.03 & 0.98 & 1.05 & 0.99 & 0.96 \\
\hline & FA & 1.03 & 1.11 & 1.08 & 1.06 & 0.93 & 0.98 & 0.95 & 0.95 & 0.98 \\
\hline
\end{tabular}

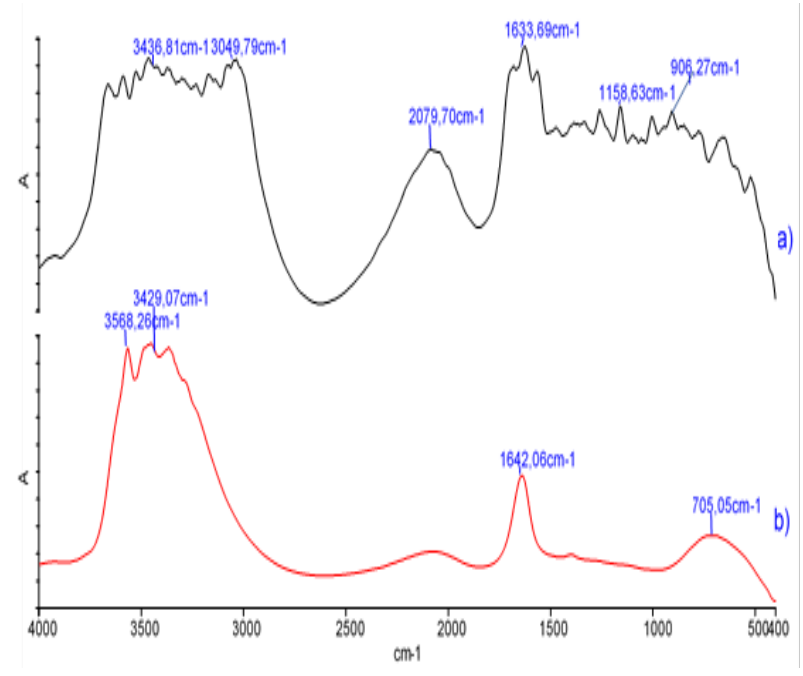

Fig. 2. FTIR spectra of $A H$ for P1_2 (a) and Pl_1 (b).

\subsection{Germination Index}

The HS, mainly the HA have several applications, such as fertilizers and land correctives, and may be applied in soils however its toxicity must be previously evaluated. The extracts from P1_2 were diluted to achieve low electric conductivity $(<4 \mathrm{mS} / \mathrm{cm})$ and were registered germination index of $115 \%$ for HS and $68 \%$ for HA. These GI values were lower than the value obtained for HS commercial liquid fertilizer Humistar ${ }^{\circledR}$ that reached $154 \%$. It is possible to said that HS and HA showed absence of phytotoxicity because the GI are greater than $60 \%$ [30] and confirmed that the humic susbtances have a positive effect in the plant growth [31]. Overall, it seems that leachate may be used to produce liquid organic fertilizers an important way to valuing this type of waste.

\section{Conclusions}

In this work, it has been extracted HS and fractionated in humic and fulvic acids from two landfills with different landfilling ages and these fractions were characterized.
The HS content in the leachates was higher than the typical values found in the natural aquatic humic sources. It was identified that the leachate HS, HA and FA aromatic components increased with increasing landfilling age. These results suggest that the degree of humification increased as the landfilling age increased. All the HS showed a high aromaticity and humification degree. The HS extracts regardless of their source presents similar structural composition. The functional groups found are in agreement with the literature: phenols, alcohols, carboxylic groups, aliphatic structures, among others. It was found that HA are constituted by organic matter with a higher aromatic degree than FA. The HS and HA showed absence of phytotoxicity, suggesting that may be used to produce liquid organic fertilizers.

The authors would like to express their gratitude to Instituto Politécnico de Viseu, the Center for Studies in Education, Technologies and Health (CI\&DETS) and the Portuguese Foundation for Science and Technology (FCT).

\section{References}

1. S. Renou, J.G. Givaudan, S. Poulain, F. Dirassouyan, P. Moulin, Journal of Hazardous Materials 150, 468493 (2008)

2. L. Zhang, A. Li, Y. Lu, L. Yan, S. Zhong, C. Deng, Waste Management 29, 1035-1040 (2009)

3. T.F.C.V. Silva, E. Silva, A.C. Cunha-Queda, A. Fonseca, I. Saraiva, M.A. Sousa, C. Gonçalves, M.C. Alpendurada, R.A.R. Boaventura, V.P.G. Vilar, Water Research 47, 6167-6186 (2013)

4. IHSS, International Humic Substances Society, Available at: $\quad<\mathrm{http}: / / \quad \mathrm{http}: / /$ humicsubstances.org/source-materials-for-ihss-samples/ > (2017) (accessed 10.05.18)

5. M.M. Tahir, M. Khurshid, M.Z. Khan, M.Z. Abbasi, M.H. Kazmi, Pedosphere 21, 124 (2011)

6. P. Janos, Journal of Chromatography A 983, 1-18 (2003) 
7. P. Linnik, L. Malinovskaya, I. Zubenko, A. Zubko, Proc. Int. Conf. on International Humic Substances Society - From Molecular Understanding to Innovative Applications of Humic Substances, ed. Perminova, I.V. and N.A. Kulikova (Moscow) 427430 (2008)

8. E.M. Peña-Mendez, J. Havel, J. Patocka, Journal of Applied Biomedicine 3, 13-24 (2005)

9. A. Jouraiphy, S. Amir, P. Winterton, M. Gharous, JC. Revel, M. Hafidi, Bioresource Technology 99, 1066-1072 (2008)

10. American Public Health Association (APHA), Standard methods for examination of water and wastewater, 22th APHA, USA (2012)

11. E.M. Thurman, R.L. Malcom, Environmental Science \&Technology 15, 463-466 (1981)

12. M.E.F. Silva, L.T. Lemos, M.M.S. M. Bastos, O.C. Nunes, A.C. Cunha-Queda, Bioresource Technology 128, 624-632 (2013)

13. H-J. Fan, H-Y. Shu, H-S Yang, W-C. Chen, Science of the Total Environment 36125 (2006)

14. R. Zbytniewski, B. Buszewski, Bioresource Technology 96, 471 (2005)

15. J.W.C. Wong, K.F. Mak, N.W. Chan, A. Lam, A. Fang, L. X. Zhou, Q.T. Wu, X.D. Liao, Bioresource Techonology 76, 99-106 (2001)

16. E. Gieguzynska, A. Kocmit, D. Golebiewska, Humic Substances in Ecosystems, A. Zaujec, P. Bielek, S.S. Gonet, (Eds) (Nitra: Slovak Agricultural University) 35-41 (1998)

17. Z. Li, P. Kechen, P. Yongzhen, Bioresource Technology 250, 413-421 (2018)

18. Z. Liu, W. Wu, P. Shi, J. Guo, J. Cheng, Waste Management 41, 111-118 (2015)
19. J.L. Weishaar, G. Aiken, B.A. Bergamaschi, M. Fram, R. Fujii, K. Mopper, Environmental Science \& Technology 37, 4702 (2003)

20. R. Albrecht, J. Le Petit, G. Terrom, C. Périssol, Bioresource Technology 102, 4495-4500 (2011)

21. H. El Hajjouji, N. Fakharedine, G. Ait Baddi, P. Winterton, J.R. Bailly, J.C. Revel, M. Hafidi, Bioresource Technology 98, 3513-3520 (2007)

22. Y. Chen, N. Senesi, M. Schnitzer, Soil Science Society America Journal 41, 352-358 (1977)

23. A. Lguirati, G. Ait Baddi, A. El Mousadik, V. Gilard, J.C. Revel, M. Hafidi, International Biodeterioration and Biodegradation 56, 8-16 (2005)

24. K-H Kang, H.S. Shin, H. Park, Water Research 36, 4023-4032 (2002)

25. P. Castaldi, G. Alberti, R. Merella, P. Melis, Waste Management 25, 209-213 (2005)

26. S. Amir, A. Jouraiphy, A. Meddich, M.E. Gharous, P. Winterton, M. Hafidi, Journal of Hazardous Materials 177, 524-529 (2010)

27. E. Smidt, K. Meissl, Waste Management 27, 268276 (2007)

28. R. Abouelwafa, G.A. Baddi, S. Souabi, P. Winterton, J. Cegarra, M. Hafidi, Bioresource Technology 99, 8571-8577 (2008)

29. J. Coates, Interpretation of Infrared Spectra, A Practical Approach, Coates Consulting, Newton, USA, (2012)

30. A. Pera, G. Vallini, S. Frassinetti, F. Cecchi, Environmental Technology 12, 1137-1145 (1991)

31. M. Morozesk et al., Chemosphere 184, 309-317 (2017) 